
About IJMA [last updated July, $\left.1^{\text {st }}, 2021\right]$

$\checkmark$ International Journal of Medical Arts is the Official Journal of the Damietta Faculty of Medicine, AlAzhar University, Egypt

$\checkmark$ It is an International, Open Access, Double-blind, Peer-reviewed Journal

$\checkmark$ Published four times a year

$\checkmark$ The First Issue was published in July 2019

$\checkmark$ Published under the following license: Creative Commons Attribution-ShareAlike 4.0 International Public License (CC BY-SA 4.0). It had updated from the Creative Commons license [CC BY] in volume 2, Issue 4, October 2020 About IJMA

$\checkmark$ The Egyptian Knowledge Bank hosts the web site of IJMA

$\checkmark$ The Egyptian Knowledge Bank supports IJMA

$\checkmark$ IJMA follows the regulations of the International Committee of Medical Journal Editors

$\checkmark$ IJMA is indexed in the "Directory of Open Access Journals" [15 January 2021].

$\checkmark$ IJMA is indexed in JGate [29-6-2021]

$\checkmark$ IJMA is a member of the International Society of Managing and Technical Editors

$\checkmark$ Listed in "Index Copernicus", "Publons", "Academic resource index [ResearchBib]", "Electronics journal library", "Eurasian Scientific Journal Index", and "Citefactor"

$\checkmark$ IJMA introduced to the search engine [BASE] through DOAJ
Click image to reach the page

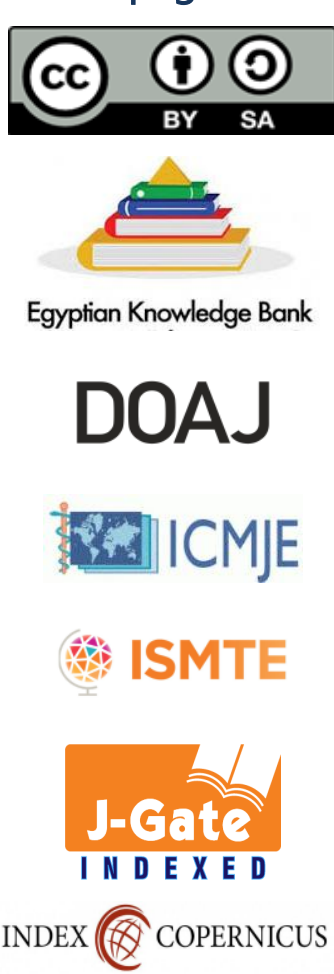

publons

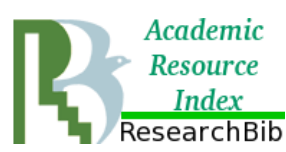

\section{EZ3 \\ .}

ESJII

CiteFactor

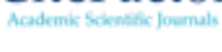

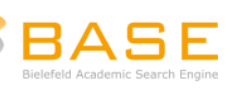




Available online at Journal Website
https://ijma.journals.ekb.eg/
Main subject [Neurosurgery]

Original Article

\title{
Endoscopic Management of Lumbar Disc Prolapse
}

\author{
Mahmoud Ramadan Mahmoud; Adel Ragab Almelesy; Mostafa Alsayed Mohamed
}

Department of Neurosurgery, Faculty of Medicine, Al-Azhar University, Egypt.

Corresponding author: Mahmoud Ramadan Mahmoud.

Email: mahmoudramadan4291@gmail.com

Submission date: November 09, 2020; Revision date: April 29, 2021; Acceptance date: July 14, 2021.

\section{ABSTRACT}

Background: Endoscopic management of lumbar disc herniation as a minimally invasive procedure become more popular around the world. Although accepted surgical outcomes of the endoscopic approach to manage lumbar disc herniation [LDH], this procedure still to be relatively challenging and needs a high learning curve, so operative failures and complications may occur.

The Aim of The Work: To assess using the endoscope in the management of lumbar disc prolapse by interlaminar approach using Easy Go and Destandau systems.

Patients and Methods: This is study included twenty patients, who had lumbar disc herniation, and operated by using Easy Go and Destandau's endoscopic systems after the failure of conservative treatment. They were included between March 2016 and April 2020. They followed up for at least three months postoperatively. All were selected from the Neurosurgery Department, Al-Azhar University Hospitals, Egypt.

Results: Low back pain was the main complaint reported by all patients. The radicular side was mainly the left side [70.0\%] and L4/L5 was the most common affected level [65.0\%]; the disc protrusion was mainly paracentral [80.0\%]. There was a significant pain reduction after surgery when compared to before surgery. The outcome was excellent for $55.0 \%$, good for $25 \%$, fair for $15 \%$ and poor for $5 \%$. Complications were in the form of unintended durotomy among $10.0 \%$, nerve injury among $10.0 \%$ and infection among 5.0\%.

Conclusion: Endoscopic lumbar discectomy through interlaminar approach by Destandau's and Easy Go systems become a golden procedure to manage lumbar disc prolapse at any level especially L5-S1 as a minimally invasive technique with some accepted complications that can easily be managed compared to classic traditional open techniques.

Keywords: Lumbar Disc Herniation; Spine Endoscopic Systems; Interlaminar Approaches; Easy Go; Destandue systems.

This is an open-access article registered under the Creative Commons, ShareAlike 4.0 International license [CC BY-SA 4.0] [https://creativecommons.org/licenses/by-sa/4.0/legalcode.

Citation: Mahmoud MR, Almelesy AR, Mohamed MA. Endoscopic Management of Lumbar Disc Prolapse. IJMA 2021; 3 [3] July-September: 16891693. [DOI: 10.21608/ijma.2021.49297.1206].

* Main subject and any subcategories have been classified according to the research topic. 


\section{INTRODUCTION}

Currently, the treatment modalities for lumbar disc herniation [LDH] comprise conventional discectomy [CD] and percutaneous endoscopic lumbar discectomy [PELD]. Because of its high success rate of approximately $90 \%$ and good result, CD is considered the standard surgical method in the management of LDH unresponsive to conservative therapy. However, $C D$ is associated with complications, including epidural scarring, destabilization of spinal canal structures, and tissue traumatization [1]. The technical advancement in endoscopes and instruments have led to the development of multiple approaches including the transforaminal, the extra foraminal and the interlaminar approach. The interlaminar approach is used in lumbar spinal stenosis and disc herniation mainly located inside the spinal canal, which is technically difficult to manage through the transforaminal technique, and especially at L5-S1 due to the large transverse processes, facets, the narrow disk space and the iliac crest ${ }^{[2-3]}$. Ruetten et al. performed for the first time the full-endoscopic discectomy by transforaminal [4] and interlaminar [5] approaches. After that, the fullendoscopic discectomy has become the most common, and minimally invasive approach for the management of lumbar disc herniation [LDH].

Due to the high rate of success, cost-effectiveness, and minimally invasive nature, fully endoscopic interlaminar discectomy [FILD] become more familiar for both surgeons and their patients for management of $\mathrm{LDH}$. This technique for treating LDH specially L5-S1, has obtained popular validation, and also produced satisfied effects of lumbar spinal stenosis [6]. Spine surgeons are accustomed to interlaminar [IL]-PELD as the anatomic orientations are similar to open surgery, although there is a learning curve. The systems for endoscopic interlaminar approach are either a conic "freehand" working channel [the Endospine by J. Destandeau] or a tubular retractor, introduced by Foley and Smith. Irrespective of the remarkable development of endoscopic procedures and instrumentation leading to good results comparable to open surgery, surgeons still have some challenges in PELD [7-9].

\section{AIM OF THE WORK}

The current study aimed to assess the usage of the endoscope in the management of lumbar disc herniation through the interlaminar approach using Easy Go and Destandau systems.

\section{PATIENTS AND METHODS}

This study, included twenty patients have lumbar disc herniation operated by using Easy Go and Destandau's endoscopic systems after the failure of conservative treatment between March 2016 and April 2020 at the Neurosurgery Department, Al-Azhar University Hospitals. All patients have lumbar disc herniation with the following criteria: Unilateral sciatica, no response to nonsurgical management for at least 1.5-month, one level of lumbar disc herniation. The following patients were excluded from this study: Cases proved to have bilateral sciatica, multiple lumbar disc herniation, and ossified disc, any degree of spinal instability, recurrent lumbar disc herniation or lumbar canal stenosis. All patients in this study were subjected to the following: Clinical assessment [history and examination, radiological assessment by MRI lumbosacral spine and plain X-ray lumbosacral spine [A-P and lateral views], operated by Easy Go and Destandau's endoscopic spine systems. Duration of post-operative stay, postoperative clinical outcome and sequel were recorded. Follow-up for at least three months postoperative and clinical outcomes were assessed by using Visual Analogue Scale [VAS] [for Mean pre- and post-operative pain score measurement]. Patients Satisfaction was measured by Modified Macnab Criteria at three months postoperatively.

Ethical considerations: The study protocol was revised and approved by the local research and ethics committee of Al-Azhar Faculty of Medicine. In addition, each patient signed an informed consent after full explanation of study protocol. The study completed in line with research ethics code of Helsinki Declaration. The data are available on request.

Recorded data were coded and fed to the statistical package for social sciences software, to be analyzed, we used version 20.0 [SPSS Inc., Chicago, Illinois, USA]. Frequency and percentages were used to report qualitative data, while mean \pm standard deviation [SD] were used to represent quantitative variables. A one-way analysis of variance [ANOVA] used to compare multiple means. Paired sample $t$-test was used to compare different points of times of the same variable. Chi-square [ $\left.\mathrm{x}^{2}\right]$ was used to test association between categorical parameters. The $p$-value was considered significant if $<0.05$.

\section{RESULTS}

This study includes 20 patients with age ranged $25-53$ with mean $35.65 \pm 7.63$ years. There were 7 females [35\%] and 13 males [65\%]. Low back pain [LBP] was reported in all patients. The radicular side was mainly the left side [70.0\%] and L4/L5 was the most common affected level [65.0\%]; the disc protrusion was mainly paracentral [80.0\%] and the system used was divided equally $[50 \%$ for Destandue and $50 \%$ for Easy Go] [Table 1]. In the current work, there was statistically a significant reduction in the visual analogue scale immediately postoperative when compared to the preoperative values and at three months 
when compared to values before or immediately after surgery [table 2]. Regarding the outcome at the end of the third postoperative month, it was excellent for $55.0 \%$, good for $25 \%$, fair for $15 \%$ and poor for $5 \%$ [Table 3]. Poor criteria reported in the case of complete nerve injury and fair criteria cases are the 2 cases' with dural injury [one of them was repaired by open surgery and the other was associated with temporarily impaired nerve function] and the case of recurrence.

Regarding complications, there was unintended durotomy among $10.0 \%$, nerve injury among $10.0 \%$ and infection among $5.0 \%$. The intraoperative blood loss ranged between 25 and $150 \mathrm{ml}$, while the length of hospital stay

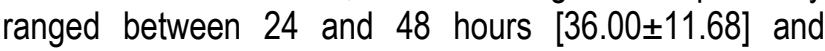
recurrence was reported in $5.0 \%$ [table 4].

Table [1]: Patient and disease characteristics among study populations

\begin{tabular}{|c|c|c|}
\hline \multicolumn{2}{|l|}{ Variable } & Statistics \\
\hline \multicolumn{2}{|c|}{ Age [years] [mean \pm SD; Minimum - Maximum] } & $35.65 \pm 7.63 ; 25-53$ \\
\hline \multirow{2}{*}{$\begin{array}{l}\text { Sex } \\
{[n, \%]}\end{array}$} & Female & $7[35.0 \%]$ \\
\hline & Male & $13[65.0 \%]$ \\
\hline \multirow{2}{*}{$\begin{array}{l}\text { LBP } \\
{[n, \%]}\end{array}$} & Yes & $20[100.0 \%]$ \\
\hline & No & $0[0.0 \%]$ \\
\hline \multirow{2}{*}{$\begin{array}{l}\text { Radicular side } \\
{[\mathrm{n}, \%]}\end{array}$} & Left & $14[70.0 \%]$ \\
\hline & Right & $6[30.0 \%]$ \\
\hline \multirow{2}{*}{$\begin{array}{l}\text { Level of disc prolapse } \\
{[n, \%]}\end{array}$} & $L 4 / 5$ & $13[65.0 \%]$ \\
\hline & L5/S1 & $7[35.0 \%]$ \\
\hline \multirow{2}{*}{$\begin{array}{l}\text { Type of disc protrusion } \\
{[\mathrm{n}, \%]}\end{array}$} & Central & $4[20.0 \%]$ \\
\hline & Para central & $16[80.0 \%]$ \\
\hline \multirow{2}{*}{$\begin{array}{l}\text { Type of system } \\
{[n, \%]}\end{array}$} & Destandue & $10[50.0 \%]$ \\
\hline & Easy Go & $10[50.0 \%]$ \\
\hline
\end{tabular}

Table [2]: Comparison between pre-management and post-management according to their visual analogue scale [n=20].

\begin{tabular}{|l|c|c|c|c|c|}
\hline \multicolumn{1}{|c|}{ Visual analogue scale [VAS] } & Range & Mean \pm SD & Difference & t-test & $p$-value \\
\hline Pre-operative & $6-9$ & $7.50 \pm 1.00$ & & & \\
\hline Immediate Post-operative & $0-7$ & $2.60 \pm 1.96$ & $4.85 \pm 1.93$ & 8.682 & $<0.001^{*}$ \\
\hline After 3 months & $0-7$ & $0.75 \pm 1.62$ & $6.75 \pm 2.25$ & 12.682 & $<0.001^{*}$ \\
\hline
\end{tabular}

Using: Paired Sample t-test; * significant difference

Table [3]: Distribution of patients according to their evaluation by Modified Macnab Criteria at the end of the postoperative third month $[\mathrm{n}=20]$.

\begin{tabular}{|l|c|}
\hline \multicolumn{1}{|c|}{ Modified Macnab Criteria } & Total [n=20] \\
\hline Excellent & $11[55.0 \%]$ \\
\hline Good & $5[25.0 \%]$ \\
\hline Fair & $3[15 \%]$ \\
\hline Poor & $1[5.0 \%]$ \\
\hline
\end{tabular}

Table [4]: Distribution of patients according to their outcome [ $\mathrm{n}=20]$.

\begin{tabular}{|l|l|c|}
\hline & \multicolumn{1}{|c|}{ Modified Macnab Criteria } & Total [n=20] \\
\hline \multirow{2}{*}{ Complications } & Unintended durotomy & $2[10.0 \%]$ \\
\cline { 2 - 3 } & Nerve injury & $2[10.0 \%]$ \\
\cline { 2 - 3 } & Infection & $1[5.0 \%]$ \\
\hline Blood loss [ml] [mean \pm SD; Minimum - Maximum] & $69.00 \pm 29.00 ; 25-150$ \\
\hline \multicolumn{2}{|l|}{ Length of hospital stay [hour] [mean \pm SD; Minimum - Maximum] } & $36.00 \pm 11.68 ; 24-48$ \\
\hline Recurrence & $1[5.0 \%]$ \\
\hline
\end{tabular}

\section{DISCUSSION}

Open surgery still the ideal technique for treating lumbar disc herniation. However, the disadvantages of this surgery are the massive retraction and dissection of back muscles, more operative consumption of time, larger scars and bone removal [10]. The current study aimed to assess the results of endoscopic management of lumbar disc herniation. Overall, the results were excellent for $55.0 \%$, good for $25 \%$, fair for $15 \%$ and poor for $5 \%$; with a statistically significant pain reduction after surgery, and pain reduction continued until the end of the third month after surgery. The complications were in the form of unintended durotomy among $10.0 \%$, nerve injury among $10.0 \%$ and infection among $5.0 \%$. There was mild intraoperative blood loss with a reasonable time of postoperative hospital stay duration. These data reflected the efficacy and relative safety of the procedure. Choi et al. [11] reported that, for full endoscopic inter-laminar discectomy, the complications rate was $18.5 \%$ [compared to $25.0 \%$ in the current one]. Epstein ${ }^{[12]}$ reported that, surgeries under the direct vision could better 
distinguish between the nerve root and other tissues. However, nerve root injury remains one of the common complications of full endoscopic lumbar discectomy. In our study we have two cases $10 \%$ of unintended accidental nerve injury, one of them was just transient impairment of nerve function and cause partial foot drop that improved by physiotherapy and this patient return to work and daily activities after three months; the other patient was complete nerve injury with foot drop that not improved after two years of follow-up.

In studies reported by Zhou et al. [13], nerve root injury occurred in $1.2 \%$ of cases. Choi et al. [14] noted that the working sheath could crush the exiting nerve root during the operation, and thus a prolonged operative time could lead to nerve irritation. Furthermore, motor weakness and temporary dysesthesia was reported as common complications in percutaneous endoscopic interlaminar discectomy [PELD]. The complications incidence was 2.00$6.53 \%$ according to previous study of Lee et al. [15]. Other common complications that have been reported in the literature include dural injuries, which are very serious complication of FILD [16-17]. Patients with small tears may be asymptomatic and may only need bed rest with a pressure dressing. However, patients with larger tearing, which can cause sciatica, uncontrolled CSF leakage, and development of a nerve root herniation, will always require secondary open repair surgery [18].

In the current research, we have two cases [10 \%] of unintended dural injury, one of them was just arachnoid bleb without CSF leakage intra-operative or post-operative, the other case was open dural injury that needed open repair at the same session. Ahn et al. ${ }^{[18]}$ reported nine patients [1.1\%] experienced symptomatic dural tears. In the series reported by Lee et al. [19] and Xia et al. ${ }^{[20]}$ reported that, there was no intraoperative incidental durotomy or leakage of cerebrospinal fluid [CSF] after surgery. In series reported by Zhou et al. [13], dural tears occurred in $0.9 \%$. In series reported by Chen et al. [21], dural tears and CSF leakage were detected in three patients due to adhesions between the calcification of disc and nerve root. However, their symptoms improved, and discharged after just one week of bed rest. Recurrent lumbar disc herniation [RLDHs] reported after different surgeries for lumbar discectomy. Phillips [22] defined RLDH as "disc herniation at the same level with a pain-free interval longer than six months after surgery regardless of whether the herniation is ipsilateral or contralateral". The risk factors include smoking, gender, obesity, and diabetes [23]. In this study we have a single case $[5 \%]$ of recurrent lumbar disc prolapse after six months that operated again by open technique. Kaushal and Sen [24] have reported RLDH rate of $5.5,5.7$, and $3 \%$. In addition, Joswig et al. [25] reported recurrent lumbar disc herniation occurred in $28 \%$. Recurrence rates after discectomy vary between 5 and $20 \%$ being independent from the technique employed. Patient satisfaction was evaluated by "Modified Macnab Criteria [MMC] after three months of the operation and was excellent in $55 \%$, good in $25 \%$, fair in $15 \%$ and poor in $5 \%$. In series reported by Oertel et al. [26], patients went back to work within 1.5 month postoperatively with a range of one up to 20 weeks. Of the patients who evaluated by MMC, $83 \%[45 / 54]$ considered their postoperative status as excellent, $13 \%$ as good [7/54], $4 \%$ were not satisfied [2/54].

In this study, the infection occurred in one case [5\%] and the patient had multiple risk factors and cured by antibiotics with medical improvement. In series reported by $\mathrm{Cao}$ et al. [27], no patient with infections after PELD. In series reported by Zhou et al. [13], there were no instances of posterior surgical site infection.

In the current trial, there was a significant decrease of pain in immediate and after three months of follow up when compared to values before surgery and no medication after three months in 16 patients [80\%], 2 cases [10\%] with interrupted medication for occasional radicular pain and another case [5\%] needed local steroid injection and another patient [5\%] with RLDH that operated again after six months. In the series reported by Oertel et al. [26], a significant radicular pain reduction permits the normal continuation of the patient's daily activities. No pain medication was reported in $89 \%$. However, $6 \%$ reported recurrent pain without evidence for recurrent disc herniation or re-stenosis. Another $5 \%$ had a recurrent disc herniation during the follow-up period and were subsequently submitted to second surgical intervention.

Despite the significant advancement of endoscopic methods and instruments leading to successful outcomes comparable to open surgery, surgeons still have some difficulty in PELD. Most are about the inadequate elimination of a disc fragment, a learning curve, recurrence rate and radiation exposure. The risk of failure may be a major obstacle to perform PELD. In addition, PELD procedure and experience can affect the success of the technique. During the phase of steep learning curve, longer operative times are needed and the incidence of complications may be higher than those reported for more expert surgeons ${ }^{[14]}$.

One of the driving forces behind the minimal invasive spine surgery is economics, shorter hospital stay, reduced postoperative morbidity, and quicker recovery times. Depth perception in these techniques comes from experience rather than observation. Hence, surgeons keen to learn these techniques must combine these procedures during the early phase of learning with standard procedures in clinical practice ${ }^{24]}$.

In conclusion, the current study revealed the effectiveness of endoscopic management of lumbar disc 
herniation. In addition, it is a relatively safe procedure with low complications rate. Thus, we recommend this technique to replace the traditional open surgery, unless there is absolute contraindication.

Financial and Non-financial Relationships and Activities of Interest

None

\section{REFERENCES}

1. Alvi MA, Kerezoudis P, Wahood W, Goyal A, Bydon M. Operative Approaches for Lumbar Disc Herniation: A Systematic Review and Multiple Treatment Meta-Analysis of Conventional and Minimally Invasive Surgeries. World Neurosurg. 2018 Jun; 114:391-407.e2. [DOI: 10.1016/j.wneu. 2018.02.156].

2. Guodong Y, Chong W, Shiqin L. Comparative analysis of therapeutic efficiency and radiographic measurement between the transforaminal approach and the interlaminar approach in percutaneous endoscopic discectomy. Turk Neurosurg. $2020 \mathrm{Jul} 27$. [DOI: 10.5137/1019-5149.JTN. 30241-20.4].

3. Wei H, Shunli K, Zehua J, Tengfei Z, Yidong L, Rusen Z. Comparative Study of Three Minimally Invasive Surgical Approaches For the Treatment of L5/S1 Lumbar Intervertebral Disc Herniation. Turk Neurosurg. 2020 May 13. [DOI: 10.5137/1019-5149.JTN.2953920.2]. Epub ahead of print.

4. Ruetten S, Komp M, Godolias G. An extreme lateral access for the surgery of lumbar disc herniations inside the spinal canal using the full-endoscopic uniportal transforaminal approach-technique and prospective results of 463 patients. Spine [Phila Pa 1976]. 2005 Nov 15; 30[22]:2570-8. [DOI: 10.1097/01.brs. 0000186327.21435. cc].

5. Ruetten S, Komp M, Godolias G. A New full-endoscopic technique for the interlaminar operation of lumbar disc herniations using 6-mm endoscopes: prospective 2-year results of 331 patients. Minim Invasive Neurosurg. 2006 Apr;49[2]:80-7. [DOI: 10.1055/s-2006932172].

6. Komp M, Hahn P, Oezdemir S, Giannakopoulos A, Heikenfeld R, Kasch R, Merk H, Godolias G, Ruetten S. Bilateral spinal decompression of lumbar central stenosis with the full-endoscopic interlaminar versus microsurgical laminotomy technique: a prospective, randomized, controlled study. Pain Physician. 2015 JanFeb; 18[1]:61-70. [PMID: 25675060].

7. Kim M, Lee S, Kim HS, Park S, Shim SY, Lim DJ. A Comparison of Percutaneous Endoscopic Lumbar Discectomy and Open Lumbar Microdiscectomy for Lumbar Disc Herniation in the Korean: A MetaAnalysis. Biomed Res Int. 2018 Aug 7; 2018:9073460. [DOI: 10.1155/ 2018/9073460].

8. Liu X, Yuan S, Tian Y, Wang L, Gong L, Zheng Y, Li J. Comparison of percutaneous endoscopic transforaminal discectomy, microendoscopic discectomy, and micro-discectomy for symptomatic lumbar disc herniation: minimum 2-year follow-up results. J Neurosurg Spine. 2018; 28[3]:317-325. [DOI: 10.3171/2017.6. SPINE172].

9. Ahn SS, Kim SH, Kim DW, Lee BH. Comparison of Outcomes of Percutaneous Endoscopic Lumbar Discectomy and Open Lumbar Microdiscectomy for Young Adults. World Neurosurg. 2016; 86:2508. [DOI: 10.1016/j.wneu. 2015.09.047].

10. Calikoglu C, Cakir M. Open Discectomy vs. Microdiscectomy: Results from 519 patients operated for lumbar disc herniation. Eurasian $\mathrm{J}$ Med. 2018; 50 [3]:178-181. [DOI:10.5152/eurasianjmed.2018.1801 6].

11. Choi I, Ahn JO, So WS, Lee SJ, Choi IJ, Kim H. Exiting root injury in transforaminal endoscopic discectomy: preoperative image considerations for safety. Eur Spine J. 2013 Nov; 22 [11]:2481-7. [DOI: 10.1007/s00586-013-2849-7]
12. Epstein NE. More nerve root injuries occur with minimally invasive lumbar surgery: Let's tell someone. Surg Neurol Int. 2016 Jan 25; 7[Suppl 3]:S96-S101. [DOI: 10.4103/2152-7806.174896].

13. Zhou C, Zhang G, Panchal RR, Ren X, Xiang H, Xuexiao M, et al. Unique complications of percutaneous endoscopic lumbar discectomy and percutaneous endoscopic interlaminar discectomy. Pain Physician. 2018 Mar; 21 [2]: E105-E112. [PMID: 29565953].

14. Choi KC, Lee JH, Kim JS, Sabal LA, Lee S, Kim H, Lee SH. Unsuccessful percutaneous endoscopic lumbar discectomy: a singlecenter experience of 10,228 cases. Neurosurgery. 2015 Apr; 76[4]: 372-80; discussion 380-1. [DOI: 10.1227/NEU. 0000000000000628].

15. Lee CW, Yoon KJ, Ha SS, Kang JK. Foraminoplastic Superior Vertebral Notch Approach with Reamers in Percutaneous Endoscopic Lumbar Discectomy: Technical Note and Clinical Outcome in Limited Indications of Percutaneous Endoscopic Lumbar Discectomy. J Korean Neurosurg Soc. 2016; 59[2]:172-81. [DOI: 10.3340/jkns.2016.59.2.172].

16. Grannum S, Patel MS, Attar F, Newey M. Dural tears in primary decompressive lumbar surgery. Is primary repair necessary for a good outcome? Eur Spine J. 2014; 23 [4]: 904-8. [DOI: 10.1007/ s00586-013-3159-9].

17. Bosacco SJ, Gardner MJ, Guille JT. Evaluation and treatment of dural tears in lumbar spine surgery: a review. Clin Orthop Relat Res. 2001; [389]:238-47. [DOI: 10.1097/00003086-200108000-00033].

18. Ahn Y, Lee HY, Lee SH, Lee JH. Dural tears in percutaneous endoscopic lumbar discectomy. Eur Spine J. 2011 Jan; 20[1]:58-64. [DOI 10.1007/s00586-010-1493-8].

19. Lee DY, Shim CS, Ahn Y, Choi YG, Kim HJ, Lee SH. Comparison of percutaneous endoscopic lumbar discectomy and open lumbar microdiscectomy for recurrent disc herniation. J Korean Neurosurg Soc. 2009; 46[6]:515-21. [DOI: 10.3340/jkns.2009.46. 6.515]

20. Xia XP, Chen HL, Cheng HB. Prevalence of adjacent segment degeneration after spine surgery: a systematic review and metaanalysis. Spine [Phila Pa 1976]. 2013 Apr 1; 38 [7]: 597-608. [DOI: 10.1097/BRS.0b013e318273a2ea].

21. Chen $Y$, Wang JX, Sun $B$, Cao $P$, Tian $Y$, Shen $X L$, et al. Percutaneous Endoscopic Lumbar Discectomy in Treating Calcified Lumbar Intervertebral Disc Herniation. World Neurosurg. 2019; 122:e1449-e1456. [DOI: 10.1016/i.wneu. 2018.11.083].

22. Phillips FM. CORR Insights [®]: Recurrent Versus Primary Lumbar Disc Herniation Surgery: Patient-reported Outcomes in the Swedish Spine Register Swespine. Clin Orthop Relat Res. 2015; 473[6]:19857. [DOI: 10.1007/s11999-014-3669-8].

23. Huang W, Han Z, Liu J, Yu L, Yu X. Risk Factors for Recurrent Lumbar Disc Herniation: A Systematic Review and Meta-Analysis. Medicine [Baltimore]. 2016; 95[2]: e2378. [DOI: 10.1097/MD.000000000000 2378].

24. Kaushal M, Sen R. Posterior endoscopic discectomy: Results in 300 patients. Indian J Orthop. 2012; 46[1]:81-5. [DOI: 10.4103/00195413.91640].

25. Joswig $H$, Richter $H$, Haile SR, Hildebrandt G, Fournier JY. Introducing Interlaminar Full-Endoscopic Lumbar Discectomy: A Critical Analysis of Complications, Recurrence Rates, and Outcome in View of Two Spinal Surgeons' Learning Curves. J Neurol Surg A Cent Eur Neurosurg. 2016 Sep; 77[5]:406-15. [DOI: 10.1055/s-00351570343].

26. Oertel JM, Mondorf $Y$, Gaab MR. A new endoscopic spine system: the first results with "Easy GO". Acta Neurochir [Wien]. 2009 Sep; 151[9]:1027-33. [DOI: 10.1007/s00701-009-0454-7].

27. Cao J, Huang W, Wu T, Jia J, Cheng X. Percutaneous endoscopic lumbar discectomy for lumbar disc herniation as day surgery - shortterm clinical results of 235 consecutive cases. Medicine [Baltimore]. 2019; 98[49]:e18064. [DOI: 10.1097/MD.0000000000018064]. 

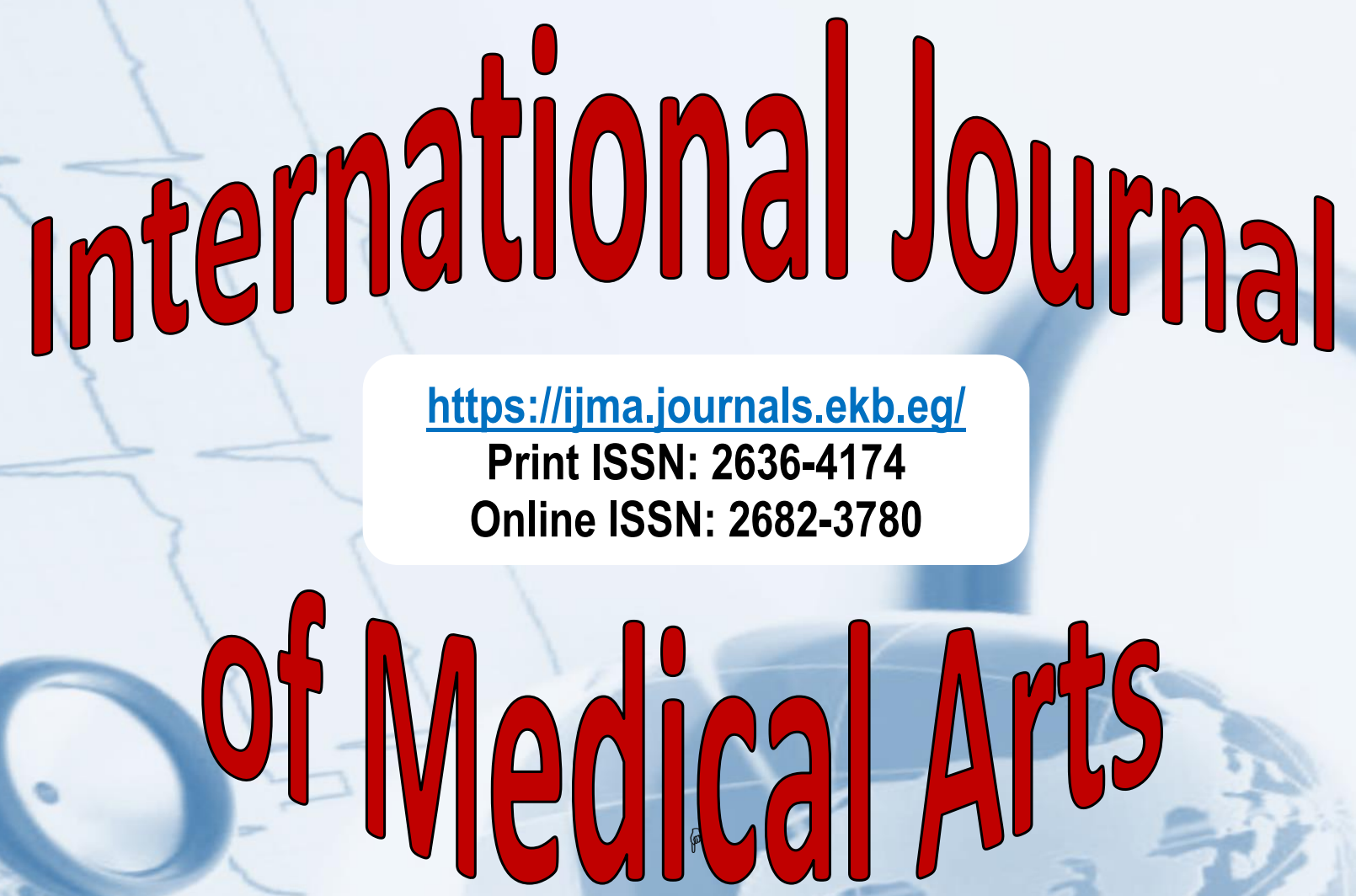